\title{
COMPLICAÇÃO RARA E REVERSIVEL DE SÍNDROME CONVULSIVA: HIPOTONIA GENERALIZADA E ALTERAÇÕES DA ATIVIDADE INTELECTUAL
}

\author{
Michel PierRe LisON* \\ M. V. Moura RIBEIRo** \\ DÉCIO MEGA **
}

$\mathrm{Na}$ evolução de uma síndrome convulsiva é extremamente raro o aparecimento de um quadro clínico reversível, caracterizado por astenia muscular com hipotonia global associada a modificações da atividade intelectual. Por êste motivo julgamos de interêsse relatar a observação seguinte.

\section{OBSERVAÇÃO}

A.B., Reg. 28.696, com um ano de idade, sexo masculino, branco, atendido, pela primeira vez, em julho de 1963. Nascido de parto normal, o paciente apresentou sua primeira convulsāo aos 2 meses de idade. As manifestações convulsivas sempre tiveram as mesmas caracteristicas; eram observadas durante o sono e precedidas por um grito seguido por contrações tônico-clônicas generalizadas. A familia refere que, freqüentemente, a criança desviada os globos oculares para a esquerda durante êsses episódios. As crises nunca tiveram relação evidente com períodos de hipertermia. As convulsões tornaram-se extremamente freqüentes, a tal ponto que raramente a criança passava uma noite sem uma ou várias crises. $O$ estado do doente nāo se modificou até os 8 meses de idade, quando passou a receber $30 \mathrm{mg}$ de fenobarbital por dia. O pediatra, consultado na época, notou desenvolvimentos neuromotor e mental compativeis com a idade do paciente. Os resultados imediatos do tratamento foram animadores. As crises se reduziram a duas por mês, em média. Nessas condiçōes o paciente passou a ser seguido no ambulatório de Neurologia, onde foram acrescentados $20 \mathrm{mg}$ diários de difenil-hidantoina (Epelin). O exame neurológico mantinha-se normal. A persistência de algumas crises isoladas, quando revisto dois meses depois, levou o neuropediatra a aumentar a dose de Epelin para $50 \mathrm{mg}$ por dia. De setembro de 1963 a maio de 1964 apenas 4 crises foram observadas. Com a idade de um ano e meio, a criança começou a andar e a balbuciar as primeiras palavras.

Em fins de julho de 1964, os familiares notaram que a criança demonstrava fadigabilidade cada vez mais acentuada durante a marcha. Com 2 anos passou a apresentar quedas freqüentes. O agravamento rápido dessa sintomatologia motivou a substituição do Epelin pela primidona (Mysoline), à razão de $125 \mathrm{mg}$ por dia. Apesar desta medida, essas perturbações se agravaram e, em outubro, o exame revelou hipotonia generalizada. O doente não se mantinha sentado e não susten-

Departamento de Neurologia da Faculdade de Medicina de Ribeirão Prêto da Universidade de Sāo Paulo (Prof. J. Armbrust-Figueiredo): * Professor Assistente; ** Instrutores. 
tava a cabeça. Não mais sorria, nem chorava e deixou de reconhecer seus familiares. Nessa ocasião foi internado. O exame de entrada revelou hipotonia global, considerável, sem perturbação evidente da motilidade ativa dos segmentos. A coordenação e os reflexos profundos apresentavam-se normais. Não havia reflexos patológłcos. O Mysoline foi progressivamente substituido pela trimetadiona (Tridione, $600 \mathrm{mg} / \mathrm{dia}$ ), acrescentando-se, a seguir, a etilmetilsuccinimida (Zarontin, 250 $\mathrm{mg} /$ dia). Desde então, houve melhora progressiva, recebendo alta em inicio de novembro.

Exames complementares - Liquido cefalorraqueano normal. Radiografia do cranio normal. Hemograma: 3.800 .000 eritrócitos por $\mathrm{mm}^{3} ; 5.600$ leucócitos por $\mathrm{mm}^{3}$ (59\% de neutrófilos, $2 \%$ de eosinófilos, $1 \%$ de basófilos, $34 \%$ de linfócitos, $4 \%$ de monócitos). Hemossedimentação: $16 \mathrm{~mm}$ na primeira hora. No sangue: uréia $15 \mathrm{mg} \%$; glicose $76 \mathrm{mg} \%$. Teste de fenilcetonúria: negativo.

A melhora se acentuou nas semanas seguintes. Em janeiro de 1965, o paciente já se mantinha sentado, com boa sustentação da cabeça. Um mês após, mantinha-se em pé, sem apoio. Aos poucos reiniciou a marcha e voltou a falar. Obedecia às ordens simples, manipulava os objetos e reconhecia seus familiares. Ativo, brincava e respondia quando chamado. Ao exame constatou-se desaparecimento completo da hipotonia.

O exame psicológico (Dra. T. Braga), avaliado pela escala de desenvolvimento de Gesell, revelou então que a conduta motora, a adaptação para com os objetos, a linguagem e a sociabilidade correspondiam à idade psicológica de 15 meses. Dois meses depois, os diferentes dominios explorados atingiram o nivel de 18 meses. Este último exame foi realizado no decorrer de ligeiro agravamento da sintomatologia.

E preciso salientar que não houve convulsōes no decorrer da evolução do quadro hipotônico.

Estudo eletrencefalográfico - O primeiro exame data de 29 de setembro de 1964, quando a criança tinha 26 meses de idade. O traçado, realizado durante o sono barbitúrico (Seconal, $100 \mathrm{mg}$ ), mostrou substituição dos ritmos normais por uma atividade paroxística permanente, constituida por ondas rápidas, difásicas, de grande potencial, seguidas por ondas lentas. Esses complexos espicula-onda, de 1 a 2 ciclos por segundo, apresentavam topografia difusa, predominando, entretanto, ao nivel das regiões frontais (fig. 1).

Um nôvo registro, em 7 de outubro, mostrou-se idêntico. A estimulação luminosa intermitente (SLI), a estimulação acústica e a estimulação nociceptiva não modificaram o traçado.

Um terceiro traçado, em estado de vigilia, realizado em 24 de outubro, não revelou mais aquela atividade paroxistica e sim profundas modificaçōes do ritmo de base que passou a ser constituído por ondas de 3 ciclos por segundo, continuas, ao nivel das projeções frontais e rolândicas. Por vêzes, foram observados esboços de espicula-onda e, algumas vêzes, ondas "sharp" sôbre a região fronto-rolândica direita. Os ritmos em regiōes posteriores eram constitufdos por ondas de 6 ciclos por segundo, com ondas rápidas de baixo potencial, sobrepostas. A SLI não modificou o traçado (figs. 2 e 3 ).

A partir de novembro observou-se melhora progressiva do quadro eletrencefalográfico. Assim, a atividade lenta de repouso foi substituida por ondas de 14-16 ciclos por segundo, alternando com periodos de atividade de 4 a 5 ciclos por segundo. No decorrer do sono havia ainda espículas-ondas, de projeção difusa e síncrona, porém separadas por períodos de atividade irregular. As espículas-ondas apresentavam, por vêzes, distribuição assimétrica.

Em março de 1965, nôvo exame realizado durante sono barbitúrico, revelou ritmo sigma e espiculas do vértex bem evidentes. Os estimulos sensoriais provocavam o aparecimento do complexo K. Ondas "sharp" foram registradas, de modo independente, ao nível dos dois hemisférios cerebrais. Por vêzes, foram observados surtos de desorganizaçāo difusa e bilateral por ondas lentas e irregulares (fig. 4). 


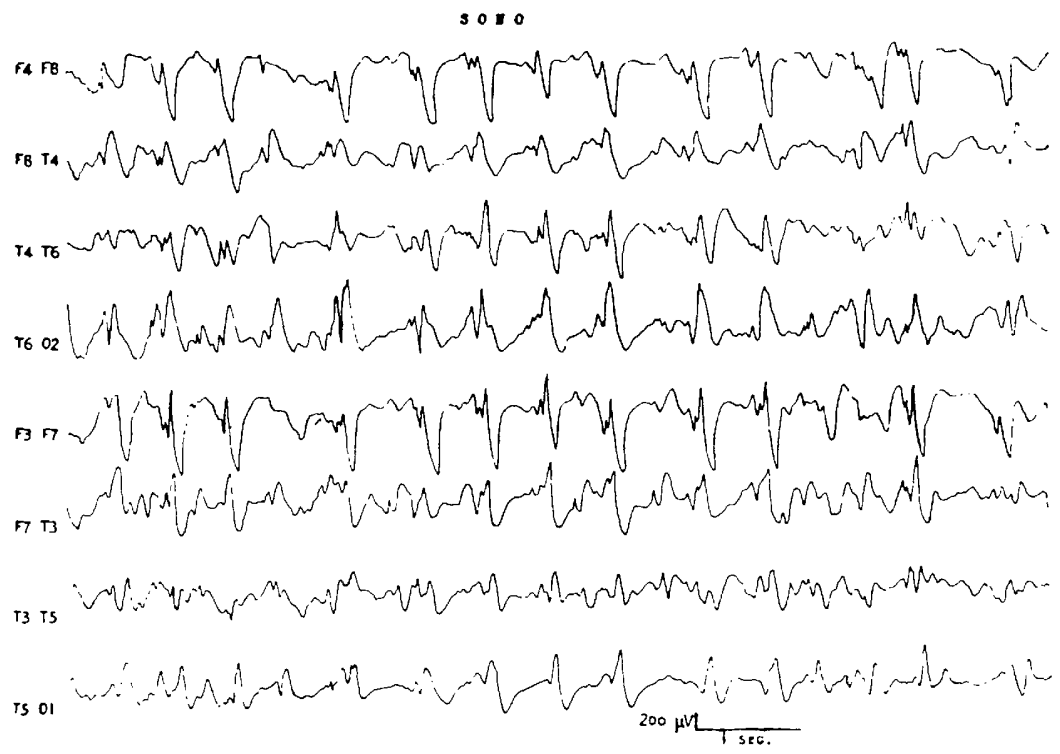

Fig. 1 - Caso A.B. Eletrencefalograma: atividade paroxistica permanente durante o sono, constituida por espicula-ondas lentas de 1-2 $\mathrm{c} / \mathrm{seg}$.

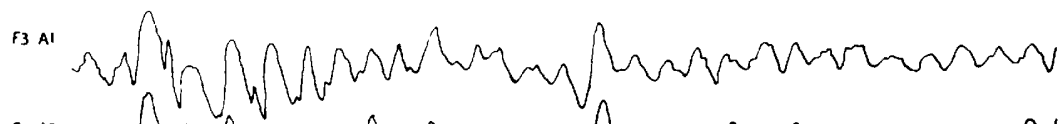

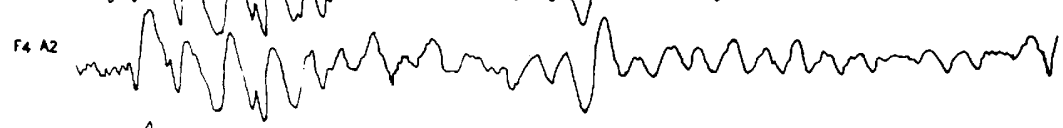

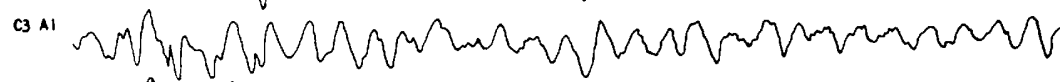

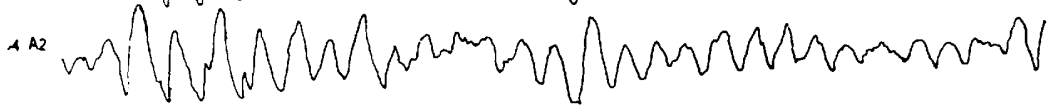

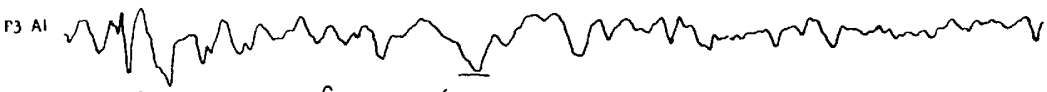

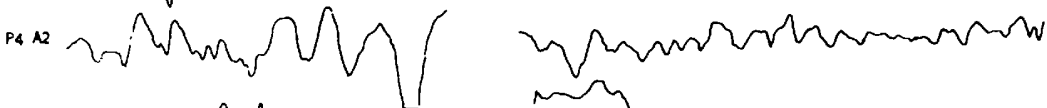

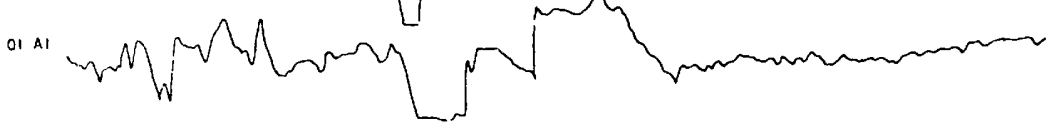

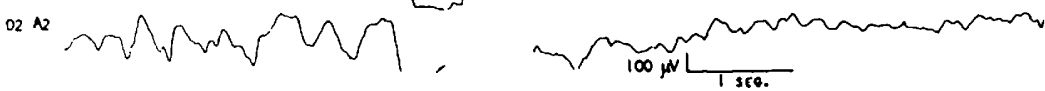

F'ig. 2 - Caso A.B. Traşado realizado $\mathrm{cm}$ vigilia. Nas regiöcs unteriores obscrva-se ritmo de $3 \mathrm{c} / \mathrm{seg}$. Nota-se igualmente a presença de esbôço de espirula de $3 \mathrm{c} / \mathrm{seg}$. 


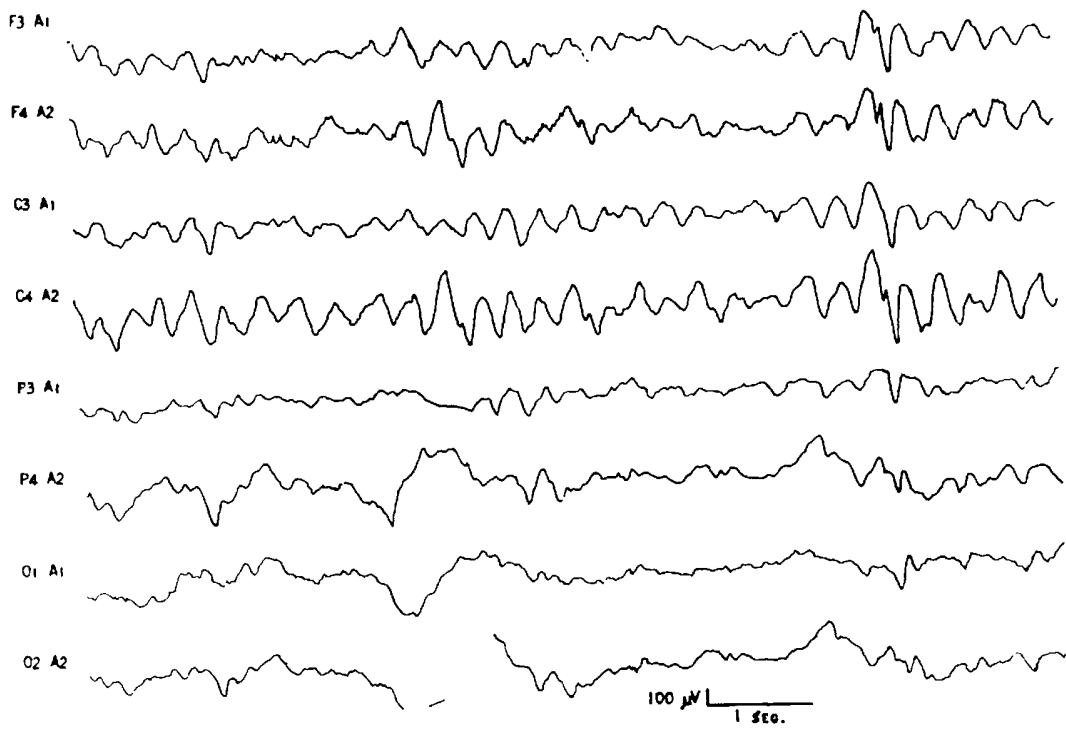

Fig. 3 - Caso A.B. Traçado realizado em vigília. Os ritmos anteriores de $3 \mathrm{c} / \mathrm{seg}$. são, por vêzes, lateralizados. A assimetria predomina à direita.

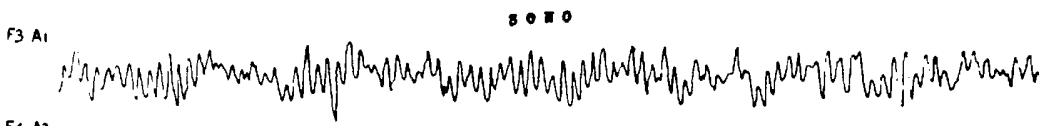
$F_{4} \mathrm{~A}_{2}$

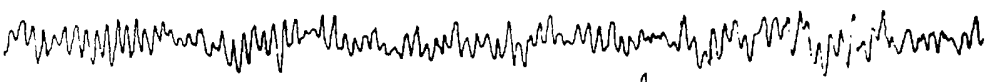

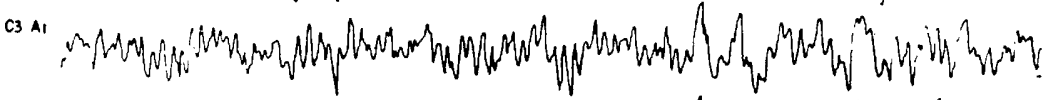

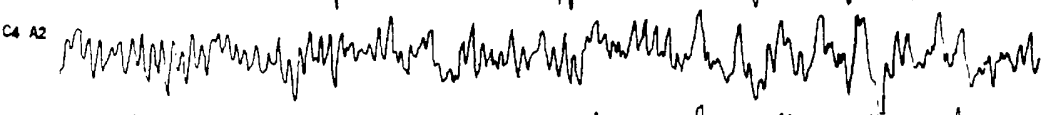

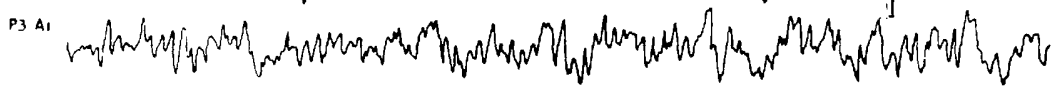

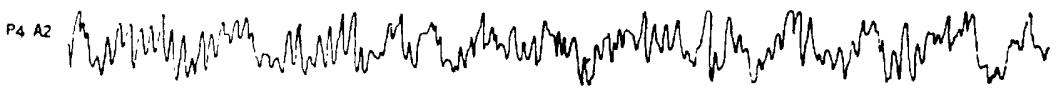

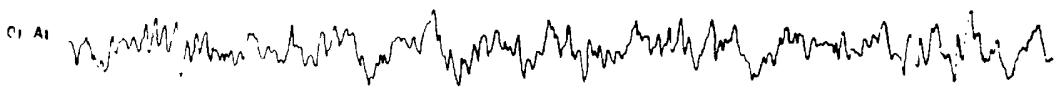

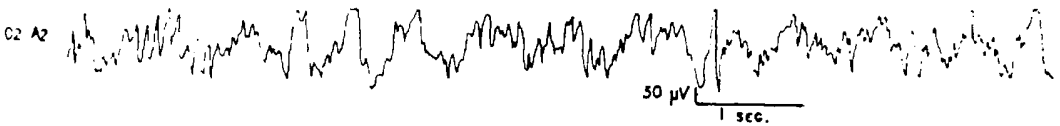

Fig. 4 - Cass A.B. Trasad" realizado durante o sono. Näo se registra mais atividade paroxistica permanente. Do ponto de vista clinico a hipotonia muscular desapareceu. 
De março de 1965 a janeiro de 1966 o doente não voltou ao Serviço. Em fins de janeiro de 1966 uma infecção respiratória justificou internação no Serviço de Pediatria, onde foi constatada broncopneumonia. As informações obtidas dos pais indicavam que não ocorrera recidiva do quadro hipotônico nem das crises convulsivas, desde março de 1965. O tratamento pelo Tridione, Zarontin e Fenobarbital não foi interrompido. O achado fortuito de eosinofilia levou o médico residente a suspender o Tridione. Curada do episódio infeccioso, a criança voltou a seu domicilio em 12 de fevereiro.

Paulatinamente, reapareceram o quadro hipotônico e a diminuição acentuada da atividade mental. A criança foi reinternada em maio de 1966 com quadro semelhante àquele observado em setembro de 1964. Os eletrencefalogramas realizados no decorrer desta nova internação revelaram alteraçōes idênticas àquelas observadas em setembro e outubro de 1964.

Uma tentativa terapêutica foi realizada com diazepam (Valium), na dose de $8 \mathrm{mg}$ por dia. Em poucos dias notou-se melhora considerável, mesmo após suspensâo do Zarontin. Em seu domicilio, seus pais notaram melhora da atividade: brincava e procurava a companhia de criancas de sua idade, e falava mais fàcilmente.

Os traçados eletrencefalográficos, realizados em junho, não mais revelavam atividade paroxistica permanente. Entretanto, algumas espiculas foram registradas ao nivel da projeção fronto-rolândica esquerda sóbre um ritmo de base pouco organizado.

Desde entāo o estado*do doente se manteve satisfatório. Entretanto surgiram crises tônico-clônicas ao nivel do membro inferior esquerdo, acompanhadas de versão ocular ipsilateral. Essas crises foram parcialmente controladas, após aumento do barbitúrico.

\section{COMENTARIOS}

Fau e Garrel ${ }^{3}$ observaram o desenvolvimento de quadro reversível de astenia e hipotonia muscular em doente com sindrome convulsiva. Êste doente apresentava crises tipo pequeno mal (PM), desde os 4 anos de idade. Aos 21 anos, coincidindo com intensificação das crises, que assumiram caráter acinético, apareceu quadro hipotônico associado a rebaixamento da atividade intelectual. O desaparecimento das crises acinéticas foi contemporâneo ao desaparecimento do quadro muscular e do quadro mental.

Além da idade, as circunstâncias de aparecimento do episódio muscular em nosso paciente foram bastante diversas. As manifestaçōes convulsivas, em nosso doente, nunca assumiram caráter de PM. Por outro lado, na época do estabelecimento do quadro muscular, as crises convulsivas estavam controladas.

O quadro eletrencefalográfico, reversível tanto no doente de Fau e Garrel, quanto no nosso, mostrava, em comum, lentidão acentuada da atividade elétrica cerebral de repouso. Em nosso paciente não encontramos descargas paroxísticas difusas no traçado de repouso, mesmo quando submetido à SLI, ao contrário do caso de Fau e Garrel. Infelizmente êsses autores não fizeram referência a traçados realizados durante o sono. Insistiremos particularmente sôbre, as importantes modificações eletrencefalográficas observadas durante o sono em nosso paciente, ou seja, o aparecimento de atividade paroxística permanente, difusa, grosseiramente simétrica e constituída 
por espículas-ondas de 1 a 2 ciclos/segundo. Traçado semelhante foi reproduzido por Gibbs e Gibbs ${ }^{6}$. Tratava-se de paciente débil mental de 16 anos, com crises GM e PM.

As disritmias observadas em nosso doente são também muito próximas àquelas encontradas nos períodos intercriticos da epilepsia miocinética grave da primeira infância, descrita por Sorel ${ }^{13}$. De acôrdo com êste autor, a expressão eletrencefalográfica do tipo PM variante seria provocada por uma agressão sôbre o sistema nervoso em determinado estado de maturação, ou num estado fisiológico definido do cérebro e de sua eletrogênese $\left(\begin{array}{lll}2 & \text { a } & 10\end{array}\right.$ anos). A hipsarritmia com espasmos em flexão seria, por sua vez, o resultado de uma agressão cerebral em estádios mais precoces, ou seja, de 0 a 1 ano.

O aparecimento de quadro hipotônico e mental reversível em criança prèviamente portadora de crises convulsivas que, embora muito freqüentes, não haviam comprometido de modo evidente o estado intelectual e o desenvolvimento neuromotor, sugere a existência de processo mórbido agindo em função de um estado de maturação cerebral. O exame psicológico de nosso doente, realizado após o periodo de estado da doença, revelou retardo evidente e sensivelmente proporcional em cada domínio explorado; em outros têrmos, o desenvolvimento de nosso paciente não evidenciou as irregularidades, lacunas e dissociações tão freqüentemente provocadas por lesões cerebrais orgânicas adquiridas. Nessas condiçōes, deve ser considerada a possibilidade de uma agressão cerebral "funcional" ou "metabólica", segundo o ponto de vista de Sorel.

Entretanto, nosso caso dificilmente pode ser explicado pela interpretação dêste autor, se considerarmos a presença constante das crises convulsivas que caracterizam o periodo de estado dos doentes de Sorel.

Por outro lado, complexos espicula-onda lenta de menos de 3 ciclos/segundo não se limitam à infância, e o caso de Gibbs e Gibbs é exemplo dêste fato. Foram igualmente descritos na encefalopatia vascular subaguda (Jones e Nevin ${ }^{9}$ ), em certas encefalites e encefalopatias portocavas (Le Beau e Gaches ${ }^{10}$ ) e no curso da evolução de um tumor talâmico (Blanc e $\operatorname{col}^{2}$ ).

Não é, portanto, preciso insistir sôbre a falta de especificidade dêste tipo de traçado, que não pode ser considerado como próprio de uma afeç̧ão particular, em função do estado de maturação fisiológica do encéfalo.

No que diz respeito à teoria reticular das crises generalizadas, deve-se admitir que "as mioclonias dependem exclusivamente da formação reticular caudal que age sôbre os neurônios motores da medula por meio das diferentes vias de projeção reticular e vestíbulo-espinal" (Gastaut e col.4).

No decorrer de uma ativação reticular global, os centros inibidores seriam menos eficazes que os centros ativadores. Passada uma fase de ativação intensa dos mecanismos reticulares ativadores em nosso doente, o tratamento instituido poderia ter provocado um efeito de sentido oposto, predominando a atividade inibidora. 
É sabido que o fenobarbital e os hidantoinatos podem precipitar o aparecimento de crises PM, assim como as dionas e as benzodiazepinas podem provocar crises generalizadas (Livingston 12, Gibbs e Anderson ${ }^{5}$ ).

O paralelismo entre a evolução eletrencefalográfica e a evolução clínica também é de difícil interpretação. O traçado de repouso do doente de Fau e Garrel ${ }^{3}$ e o de nosso paciente mostravam lentidão considerável da atividade elétrica cerebral no decorrer do periodo hipotônico. As ondas de 3 ciclos/segundo registradas ao nível das projeções anteriores, em nosso paciente, poderiam ser a expressão elétrica dos fenômenos inibidores de origem tálamo-caudada. As poucas espiculas associadas a estas ondas lentas que, como já dissemos, jamais atingiram um grau de desenvolvimento suficiente para caracterizar um complexo espícula-onda típico, representariam o resquício da atividade do sistema reticular ativador de projeção tálamo-cortical.

É interessante notar a grande semelhança entre o aspecto eletrencefalográfico de nosso caso durante a vigilia e o traçado obtido no decorrer da ativação pelo Metrazol, durante a fase das alterações paroxísticas "inespecíficas" pré-ictais. Ajmone-Marsan e Ralston ${ }^{1}$ consideram aquelas alterações, específicas dos casos de epilepsia devidas a uma manifestação centrencefálica ou a uma lesão da regiāo parassagital.

Do ponto de vista eletrencefalográfico, nosso paciente estaria submetido a uma "ativação positiva" constante, de significado análogo à ativação farmacológica experimental.

A substituição de uma atividade lenta por uma atividade de tipo espícula-onda durante o sono, sugere maior participação do sistema ativador que é, como se sabe, responsável pelo aparecimento rítmico das espículas. É útil lembrar, a propósito, que, antes do tratamento, as crises tônico-clônicas de nosso doente foram sempre noturnas, o que prova a influência do sono sôbre os fatôres ativadores. A remissão clínica do quadro hipotônico pelo tratamento com Tridione, Zarontin e, ulteriormente, Valium, depõe em favor da influência dos desequilíbrios entre fatôres inibidores $e$ ativadores da substância reticular na patogenia do quadro clínico e eletrencefalográfico de nosso caso.

O problema da origem da atividade paroxistica permanente de nosso doente requer alguns comentários. Sabe-se que as manifestações eletroclinicas generalizadas, particularmente do tipo PM variante, podem ter origem focal. Assim, focos situados na região do pólo frontal e, sobretudo, ao nível da área motora suplementar, podem provocar crises de tipo "centrencefálicas” (Tükel e Jasper ${ }^{14}$, Ajmone-Marsan e Ralston ${ }^{1) . ~ G o r d o n ~}{ }^{7}$ relata, num epiléptico, descargas PM simultâneamente com descargas focais de projeção temporal anterior. A propagação rápida dessas descargas em direção ao centrencéfalo se realiza por intermédio de certas estruturas do sistema limbico, particularmente do giro cingulado anterior (Ajmone-Marsan e Ralston $\left.{ }^{1}\right)$. O sistema responsável pelas crises PM seria constituído pelos núcleos talâmicos anteriores e medianos, o giro cingulado anterior e o cerebelo; a formação do hipocampo e as áreas entorrinais aferentes a êste sistema devem igualmente ser incluidas (Lennox e Robinson ${ }^{11}$ ). 
O exame de nossos traçados, em vigília e no sono, mostra, ao longo das montagens coronárias, uma reversão de fase simples ao nível do vértex (fig. 5 ).
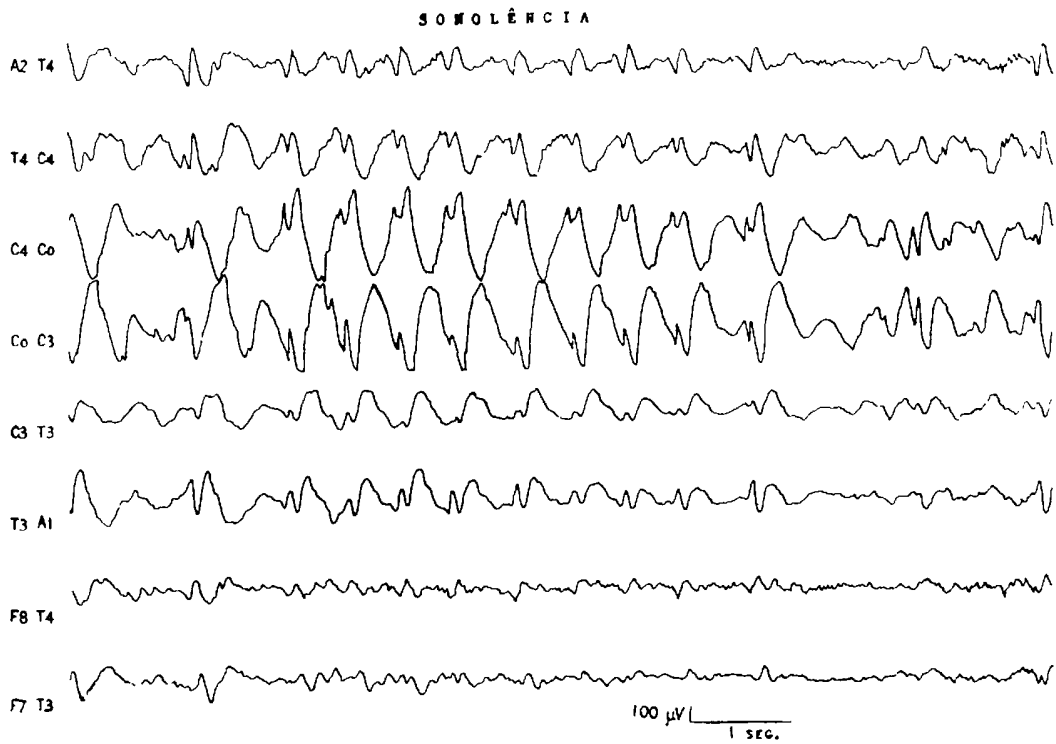

Fig. 5 - Caso A.B. No decorrer da sonolência observa-se a presença de espicula-onda lenta predominando ao nivel das projeções rolândicas. Ao longo da montagem coronária nota-se uma reversão de fase simples ao nivel do vértex.

De acôrdo com Tükel e Jasper ${ }^{14}$, êste aspecto eletrencefalográfico corresponde a uma sincronização bilateral secundária a um foco cortical unilateral. Além disso, a freqüência de 1 a 2 ciclos/segundo, a irregularidade das descargas e a assimetria ocasional de voltagem entre os dois hemisférios, depõem em favor de uma sincronização secundária bilateral. A presença de ondas de potencial mais elevado ao nivel da região fronto-rolândica direita sugere a existência de um foco parassagital. Essa possibilidade se apoia, ainda, em alguns achados clinicos: as crises versivas oculares e as clonias localizadas ao nivel do membro inferior esquerdo. Nessa perspectiva a ação favorável do diazepam estaria relacionada com a depressão de certas estruturas do sistema límbico produzido por esta droga (Himwich e col. $\left.{ }^{8}\right)$.

Concluindo, o estudo eletroclínico de nosso doente sugere a participação predominante de uma atividade reticular inibidora. Esta atividade continua teria sido precipitada pelo esgotamento de uma atividade reticular de sentido oposto. Esse desequilíbrio transitório entre atividades reticulares teria sido favorecido pela ação de uma terapêutica agindo principalmente sôbre 
os fatôres ativadores, provàvelmente em função de um estado de maturação cerebral favorável ao desenvolvimento da atividade inibidora. A ativação reticular seria produzida através de um foco à distância, parassagital.

Dentre as manifestações convulsivas "minor" devemos isolar um tipo particular, não paroxístico, e sim contínuo, sem perturbações verdadeiras de consciência, caracterizado por um quadro hipotônico associado a rebaixamento considerável da atividade intelectual, e, do ponto de vista eletrencefalográfico, representado em vigília por uma atividade de projeção anterior de 3 ciclos/segundo. O componente ativador representado pela espícula está ausente ou apenas esboçado.

\section{RESUMO}

Os autores relatam uma síndrome hipotônica transitória com perturbações da atividade intelectual, que surgiu no decorrer da evolução de um caso de epilepsia, em criança de um ano de idade. Uma tentativa de interpretação fisiopatogênica das manifestações clínicas e eletrencefalográficas é realizada à luz dos conhecimentos atuais sôbre certas disfunções reticulares e suas respectivas expressōes bioelétricas.

\section{SUMMARY}

$A$ rare and reversible complication of a convulsive syndrome: generalized hypotonia and disturbances of intelectual capacity

A case of transitory hypotonic syndrome with disturbances of the intelectual capacity is reported. The syndrome developed during the course of epileptic seizures in a child one year old. The physiopathogenic interpretation of clinical and electroencephalographic signs is attempted on the light of the present knowledge of some reticular formation disfunctions and their bioelectric significance.

\section{RESUME}

Une rare complication réversible d'un syndrome convulsif: hypotonie généralisée et altérations de l'activité intellectuelle

Les auteurs rapportent un syndrome hypotonique transitoire avec perturbations de l'activité intellectuelle apparu au cours de l'évolution d'un cas d'épilepsie chez un enfant âgé d'un an. Une tentative d'interprétation physiopathogénique des manifestations cliniques et électroencéphalographiques est réalisée à la lumière des connaissances actuelles sur certaines disfonctions réticulaires et leurs respectives expressions bio-électriques. 


\section{REFERENCIAS}

1. AJMONE-MARSAN, C. \& RALSTON, B. L. - The Epileptic Seizure. Its Functional Morphology and Diagnostic Significance. Charles C. Thomas, Springfield (Illinois), 1957.

2. BLANC, M.; JULIEN, J.; LOISEAU, P. \& VITAL, P. - Corrélations électrocliniques à propos d'un cas d'activité EEG paroxystique permanente. Rev. Neurol. 107:461-473, 1962.

3. FAU, R. \& GARREL, S. - Crises akinétiques transitoires apparues au cours de l'évolution d'un petit mal. Rev. Neurol. 109:231-232, 1963.

4. Gastaut, H.; Regis, H. \& CHEVAllier, G. - A propos du petit mal "akinétique" de Lennox. Rev. Neurol. 103:593-598, 1960.

5. GIBBS, F. A. \& ANDERSON, E. M. - Treatment of hypsarhythmia and infantile spasms with a Librium analogue. Neurology 15:1173-1176, 1965.

6. GIBBS, F. A. \& GIBBS, E. L. - Atlas of Electroencephalography, vol. II. Addison-Wesley Publishing Co., London, 1952.

7. GORDON, N. - Petit mal epilepsy and cortical epileptogenic foci. EEG Clin. Neurophysiol. 11:151-153, 1959.

8. HIMWICH, H. E.; MORILLO, A. \& STEINER, W. G. - Drugs affecting rhinencephalic structures. J. Neuropsych. 3:15-26, 1962.

9. JONES, D. P. \& NEVIN, S. - Rapidly progressive cerebral degeneration (subacute vascular encephalopathy) with mental disorder, focal disturbances and myoclonic epilepsy. J. Neurol. Neurosurg. and Psychiat. 17:148-158, 1954.

10. LE BEAU, J. \& GACHES, J. - Diagnostic neurochirurgical et electroencéphalographique des encéphalites aigües non suppurées d'apparence primitive. Sem. Hôp. Paris 37:1217-1228, 1961.

11. LENNOX, M. A. \& ROBINSON, F. - Cingulate-cerebellar mechanisms in the physiological pathogenesis of epilepsy. EEG. Clin. Neurophysiol. 3:197-206, 1951.

12. LIVINGSTON, S. - The Diagnostic and Treatment of Convulsives Disorders in Children. Charles C. Thomas, Springfield (Illinois), 1954.

13. SOREL, L. - L'épilepsie myokinétique grave de la première enfance avec pointe-onde lent (petit mal variant) et son traitement. Rev. Neurol. 110: 215-223, 1964.

14. TUKEL, K. \& JASPER, H. - The electroencephalogram in parasagital lesions. EEG. Clin. Neurophysiol. 4:481-494, 1954.

Departamento de Neurologia - Faruldade de Medicina de Ribeirão Prêto Ribeirĩo Prêto, SP - Brasil. 